Cuadernos de Filología Clásica. Estudios Latinos

ISSN: 1131-9062

http://dx.doi.org/10.5209/CFCL.57807

\title{
Sobre el conocimiento de Plauto y Terencio en Italia y España en el siglo XV
}

Devid Paolini $^{1}$

Recibido: 5 de diciembre de 2016 / Aceptado: 7 de marzo de 2017

Resumen. Las comedias de Terencio y, en menor medida, las de Plauto se utilizaron a lo largo de los siglos XIV y XV para el aprendizaje del latín. Si, por un lado, en la península italiana las informaciones que tenemos acerca de esta didáctica es considerable, por el otro muy escuetos son los datos que se conservan en España -aunque un sinfín de investigaciones sigue repitiendo que las comedias latinas clásicas también se estudiaban allí. El objetivo principal del presente trabajo es, por lo tanto, el de revisar toda una serie de estudios que se han ocupado del asunto y proponer un acercamiento más cauto a futuros investigadores que quieran tratar esta cuestión.

Palabras clave: Plauto; Terencio; Italia; España.

[en] On the knowledge of Plautus and Terentius in Italy and Spain in the 15th century

Abstract. The comedies of Terence and, to a lesser extent, Plautus were used throughout the $14^{\text {th }}$ and $15^{\text {th }}$ centuries to learn Latin. While for the Italian peninsula the information we have about this way of teaching is considerable, very little data are preserved for Spain -although many scholars keep repeating that classical Latin comedies were also studied there. The main objective of this paper is, therefore, the review of a number of studies that have dealt with this matter and propose a more cautious approach to future researchers wishing to address this issue.

Keywords: Plautus; Terence; Italy; Spain.

Cómo citar: Paolini, D., «Sobre el conocimiento de Plauto y Terencio en Italia y España en el siglo XV», Cuad. Filol. Clás. Estud. Lat. 37.2 (2017), 303-316.

El objetivo del presente trabajo rueda alrededor de estos dos ejes principales: el posible uso de los textos de Plauto y Terencio en la enseñanza del latín; y la fortuna y el conocimiento de las comedias de los dos durante el siglo XV, tanto en la península italiana como en Castilla².

1 The City College of New York.

dpaolini@ccny.cuny.edu.

2 Una primera versión del presente trabajo, aquí ampliada, mejorada y corregida, fue leída en Ciudad de México durante el congreso Medievalia, XIII Jornadas Medievales, que tuvo lugar en la Universidad Nacional Autónoma de México a finales de septiembre de 2010. Este artículo complementa otra investigación nuestra (Paolini 2011). Ambas investigaciones tienen el mismo doble objetivo: por un lado mostrar la diferente fortuna que tuvieron las comedias de los dos dramaturgos latinos en España e Italia a lo largo de los siglos XV y XVI; y, 
De sobra conocida es la fortuna de la que gozó Terencio en su misma época y, aún más, en los siglos siguientes. ${ }^{3}$ De hecho, la obra del Terentius noster, como lo apelaba Poggio Bracciolini (Villoresi 1994, 21, n.13) por su lenguaje puro y refinado, se estudió en las escuelas y las universidades para el aprendizaje del latín. Como ha escrito acertadamente Gil Fernández $(1984,102)$ :

Las comedias terencianas ofrecían no sólo una muestra insuperable de pureza, propiedad y elegancia de dicción, sino un ejemplo vivo de cómo hablaban los romanos. De ahí que fuera menester no sólo leerlas una y otra vez, sino aprendérselas palabra por palabra. En la enseñanza del latín, eran absolutamente necesarias.

Diferente fue el destino de Plauto. Tras un éxito inicial, fue criticado y censurado severamente por los Padres de la Iglesia a causa de sus expresiones lascivas y sus argumentos demasiados escabrosos. Fue solo a partir del Quattrocento que logró, poco a poco, recuperar su fama, de todos modos siempre menor con respecto al comediógrafo de Cartago. ${ }^{4}$

En lo tocante a Terencio como texto-base en la enseñanza del latín en la península italiana, hay referencia ya desde la segunda mitad del siglo XIV con Pietro de Moglio: oriundo de Bolonia y maestro en el estudio nativo y en Padua, nos quedan, de él, los comentarios y las apostillas de los cursos que impartió sobre las comedias terencianas y las tragedias de Séneca (Billanovich 1978, 368-73). Ya entrado el siglo XV nos encontramos con una de las figuras más representativas de la primera mitad del Quattrocento, un maestro que enseñó a toda una serie de humanistas de primera importancia y que tuvo bien presentes, en sus clases, tanto las comedias de Plauto como las de Terencio: Guarino Veronese (1370-1460). ${ }^{5}$ Después de estudiar griego en Constantinopla con Manuel Crisoloras, volvió a Italia y enseñó primero en Venecia y luego en Florencia y Verona. En 1429 llegó a Ferrara donde se quedó, trabajando como preceptor, hasta su muerte, acaecida en $1460 .{ }^{6}$ Se le consideró una auctoritas en el estudio de Plauto y fue un gran defensor de las comedias de Terencio, atacadas por los eclesiásticos en sus diatribas en contra de la literatura pagana. Tras su muerte, su hijo Battista (1435-1513) siguió las huellas paternas y después de terminar sus estudios de retórica en la Universidad de Bolonia, enseñó primero en Ferrara y luego en Mantua. En su De ordine docendi ac studendi, tratado didáctico inspirado en los métodos pedagógicos del padre, Battista Guarino recomendaba vivamente la lectura de Terencio: Ad sermonis tum puritatem et elegantiam, tum proprietatem, nemo Terentio magis

por otro, llamar la atención sobre los problemas que esta diferencia conlleva en cuanto a la génesis de Celestina (problema que podría resumirse con esta pregunta: ¿si en España no se conocían las obras de Plauto y Terencio ni la comedia humanística [se nos permita, a propósito, señalar nuestro trabajo de 2012], cómo pudo escribirse la obra maestra española que tantos puntos en común tiene con estas tradiciones dramáticas?

3 Veánse, entre otros, Sabbadini (1897), Bucchioni (1911), Pacetto (1919), Billanovich (1978), Villa (1984) y Prete (1990).

4 Se ocupa de la fortuna de los dos en época romana, Ronconi (1970). En cuanto al éxito de Plauto véanse, entre otros, Questa (1968), González-Haba (1992, 10), Conte (1984) y Bertini (1997).

5 Acerca de Guarino, véanse, entre otros, el DBI y Villoresi (1994).

6 Acerca de la importancia de Guarino en Ferrara y el lugar privilegiado que los dos comediógrafos latinos tenían en su programa pedagógico, véanse las numerosas informaciones reunidas y analizadas por Villoresi (1994). 
idoneus... Quare assiduitate legendi memoriae commendandus erit (Garin 1958, 456). Y tampoco dejaba de lado a Plauto afirmando: Plautus non ad sales modo qui vitae sunt ornamento, sed ad eloquentiam vehementer proderit ${ }^{8}$ (ib.).

También Enea Silvio Piccolomini (1405-1464), futuro papa Pio II, declaraba, en su Tractatus de liberorum educatione, la importancia del estudio de los dos cómicos latinos para mejorar la elocuencia. Así escribió: Comedi plurimum conferre ad eloquentiam possunt, cum per omnes personas et effectus eant. Ex hisce tantum duos habemus, Plautum atque Terentium ${ }^{9}$ (ib., 268).

De la enorme importancia que tuvo Terencio para los grandes maestros humanistas nos queda constancia también en Gasparino Barzizza (1360 ca.-1431) y su hijo Guiniforte (1406-1463). El primero, profesor de gramática y retórica en Pavía y luego en Padua y Milán, escribió un comentario a Terencio que, lamentablemente, se ha perdido, mientras sí se conserva un códice autógrafo (el Ambrosiano Z 55) donde reunió las sentencias de los dos cómicos (Villoresi 1994, 22, n. 16); ${ }^{10}$ el segundo fue llamado a enseñar en Novara en 1431 y en su discurso inaugural como maestro en el estudio, no hizo otra cosa sino un panegírico del comediógrafo de Cartago, impartiendo, luego, un curso sobre él y el De officiis de Cicerón ( $i b$.).

Otro gran pedagogo de la época fue Vittorino de Feltre (1378 ca.-1446), que estudió primero en Padua, con Gasparino Barzizza, y fue luego discípulo de Guarino durante su primera estancia en Venecia (1415-19). Después de alternar la enseñanza entre Venecia y Padua, se mudó a Mantua en 1422 invitado por el Marqués Gian Francesco I Gonzaga, quien le confió la educación de sus hijos. Enseguida fundó allí la primera escuela humanística de principios cristianos, en una villa que el marqués le puso a disposición llamada 'Ca' Zoiosa' y que Vittorino apodó 'Ca' Gioiosa' (es decir, 'La casa de la alegría'). Terencio, naturalmente, formaba parte de su programa didáctico y además el maestro poseía un códice con las comedias del cartaginés. ${ }^{11}$

Otro discípulo de Gasparino Barzizza, amigo de Guarino y Vittorino de Feltre, y gran humanista-pedagogo, fue Francesco Filelfo (1398-1481) que impartió su docencia en los centros culturales más importantes de la época: Milán, Venecia, Bolonia, Siena, Roma, etc. En 1429 se mudó a Florencia, donde la ciudad y sus más ilustres representantes (Cosimo de' Medici, Leonardo Bruni, Niccolò Niccoli y Ambrogio Traversari) lo habían invitado para enseñar en el estudio. Antes de su llegada había enviado a Traversari el programa del curso que quería impartir para que se anunciara entre los jóvenes florentinos: por la mañana Cicerón (las Disputaciones tusculanas y la retórica), Tito Livio, y en griego la Ilíada; y, por la tarde, Terencio, otra vez Cicerón (oraciones y epístolas), Tucídides o Jenofonte, y filosofía moral (Rossi 1992, 48; DBI).

En Florencia, Angelo Poliziano (1454-1494) fue, sin duda alguna, uno de los humanistas más eruditos que empujó al estudio de la comedia clásica y a la recuperación del teatro latino. En el curso sobre Andria de Terencio que impartió entre

«Nadie es más idóneo que Terencio para mejorar la pureza, la elegancia y la propiedad del lenguaje... Por eso será recomendable aprenderlo de memoria con una asidua lectura» (la traducción, como las siguientes, si no se especificará de otra manera, es nuestra).

8 «Plauto no solo mejorará mucho a la perspicacia, que es el ornamento de la vida, sino también a la elocuencia».

9 «Los cómicos pueden ayudar muchísimo a mejorar la elocuencia, puesto que toman en consideración a todos los personajes y los estados de ánimo. De estos tenemos dos: Plauto y Terencio».

10 Trata de los métodos pedagógicos de Gasparino Barzizza, Mercer (1979).

11 Acerca de Vittorino y su escuela véanse Giannetto (1981) y Cortesi (1980, 94-96, en particular). 
1484 y 1485, el humanista, además de analizar detenidamente el texto, se ocupó por primera vez de reconstruir la historia de la comedia desde su origen griego hasta las representaciones romanas. ${ }^{12}$ Siempre allí, ya desde 1476, en la escuela humanística de Giorgio Antonio Vespucci, amigo de Poliziano y Ficino, y tío del futuro navegador Américo, se había representado Andria de Terencio ${ }^{13}$ por el reconocido valor pedagógico que se atribuía a la recitación (Ventrone 1993, 23-4). Otros maestros de la ciudad, como Luca d'Antonio Bernardi de San Gimignano y Paolo Comparini de Prato, siguieron el ejemplo de Vespucci: el primero, que enseñó gramática en el Estudio florentino desde 1485 hasta 1498, organizó representaciones tanto de dramas suyos como de los Diálogos de Luciano y una comedia de Plauto (ib., 25 y n. 33); el segundo puso en escena con sus discípulos, el 12 de mayo de 1488, Menaechmi con un prólogo de Poliziano. ${ }^{14}$

A estas primeras representaciones con finalidades pedagógicas, siguieron, en diferentes centros culturales de la península italiana, verdaderos intentos de recuperación de la tradición dramática latina: se mencionarán, a título indicativo, las puestas en escena romanas de las comedias de Plauto y Terencio en latín organizadas por la Accademia pomponiana; y, sobre todo, la intensa activida teatral que tuvo lugar en Ferrara a partir de 1486, con la representación de la obra de los dos comediógrafos latinos traducida en vernáculo. ${ }^{15}$

De todos modos, el reflejo de esta didáctica basada en las comedias de Plauto y, sobre todo, Terencio, y también del conocimiento general muy difundido de las comedias de ambos cómicos ${ }^{16}$ se desprende de las citas, los reenvíos, la extensa imitatio y emulatio de la que fue objeto la obra de los dos comediógrafos latinos en diferentes textos de humanistas italianos del siglo XV. Será suficiente recordar las así llamadas comedias humanísticas, género que se desarrolló casi exclusivamente en la península italiana y que representa la tentativa de los eruditos del Quattrocento de escribir obras según el ejemplo de Plauto y Terencio. ${ }^{17}$ Entre estas, Chrysis de Enea Silvio

12 Lattanzi Roselli (1973) ha transcrito y preparado la edición crítica de los apuntes del curso de Poliziano. Véase, además, Ventrone (1992; 1993, 36-38, 171-177).

13 Tratan de la representación de comedias clásicas en Florencia, Del Lungo (1876), Pintor (1906) y Doglio (1971). La información acerca de la representación que tuvo lugar durante el carnaval de dicho año, viene de una carta de Pietro Cennini a Alamanno Rinuccini. Recuerda todo el episodio y señala la bibliografía fundamental, Ventrone (1993, 23 y n. 26).

14 Un análisis del prólogo que Poliziano escribió en defensa de Lorenzo el Magnífico contra los ataques de los eclesiásticos que criticaban las representaciones de comedias clásicas (Ventrone 1993, 27, 35-6), puede leerse en: Bombieri (1985), Bausi (1991) y Martelli (1993). El interés del Magnífico por las comedias clásicas está señalado también en un soneto escrito por Feo Belcari hacia 1480 donde se nos habla de Plauto y Terencio como fuentes de la elocuencia del Medici: «Nel tuo intelletto el bel Terenzio e Plauto / Versan le muse lor, como Nettunno / Le grand'acque del verno e dell'autunno, / Per farti sempre di eloquenzia lauto...» (apud Ventrone 1993, 34, n. 56).

15 Nos hemos ocupado detenidamente de la cuestión (la recuperación y el renacimiento del teatro, y los diferentes centros culturales de la península italiana) en Paolini (2011).

16 En la Politia litteraria de Angelo Decembrio, interesante retrato de la cultura humanística en la Ferrara del siglo $\mathrm{XV}$, se lee, por ejemplo, que tanto Amphitruo como Aulularia de Plauto se conocían tanto que había quien los recitaba de memoria: quarum Amphitriona, Aululariaque ita vulgatae, risusque complete sunt, ut quidam eas memoriter recitarint (apud Villoresi 1994, 51).

17 Han dedicado estudios fundamentales a la comedia humanística: Pandolfi y Artese (1965); Perosa (1965); Doglio, (1971, 1982); y, sobre todo, Stäuble (1968, 1972, 1976, 1986). Estos habrán que ponerse al día con las aportaciones de Padoan (1982, 1996); Viti (1999); Pittaluga (2001); Ruggio (2011); Chevalier (2013); y todas las nuevas ediciones críticas que la colección «Teatro umanistico» de la editorial SISMEL-Edizioni del Galluzzo está publicando desde hace unos años. 
Piccolomini se puede considerar casi un centón de las comedias Curculio y Asinaria; dependen claramente de Plauto también Stephanium de Giovanni Armonio Marso, Dolotechne de Bartolomeo Zamberti, Annularia y Bophilaria de Egidio Galli, y Philodoxeos de Leon Battista Alberti; en Philogenia de Ugolino Pisani, se encuentran unos cuantos préstamos de Terencio; lo mismo pasa con Poliscena de Leonardo de la Serrata; ${ }^{18}$ y siguen muy de cerca el patrón terenciano Paulus de Pietro Paolo Vergerio, Cauteraria de Antonio Barzizza, Fraudiphila de Antonio Cornazzano, Peregrinatio y Eugenius de Tito Livio de Frulovisi; y Poliodorus de Johannes de Vallata. ${ }^{19} \mathrm{Y}$ esto, en cuanto a comedias humanísticas.

Hay que considerar, además, la influencia que los dos dramaturgos tuvieron en los autores más importantes del Renacimiento: desde Ludovico Ariosto ${ }^{20}$ pasando por Bernardo Dovizi de Bibbiena, ${ }^{21}$ hasta llegar a Niccolò Machiavelli. ${ }^{22}$

Por último se puede citar, también, la adaptación o imitación de Captivi de Plauto que compuso Matteo Maria Boiardo (1441-1494) y que incluyó en los cantos XI-XIII del segundo libro de su Orlando innamorato (Villoresi 1994, 133-49); la influencia plautina en las facetiae de Giovanni Pontano y Poggio Bracciolini (Gil Fernández 1984, 98); las numerosas ediciones, en la península italiana, de las comedias de los dos cómicos en el último cuarto del Quattrocento (la princeps de Plauto salió en 1472 en Venecia al cuidado de Giorgio Merula); seguidas, a partir de la segunda década del siglo siguiente, por la impresión, en Venecia, de unas cuantas traducciones de los dos clásicos latinos: Menaechmi y Asinaria en 1528 y 1530; Poenulus en 1520, 1526, 1530 y 1532; Amphitruo, Casina y Mostellaria en 1530; Eunucus, 1532; $\mathrm{y}$ todas las comedias de Terencio traducidas se imprimieron numerosas veces a partir de 1533 (Orlando 1940; Padoan 1996, 56, n. 34).

En cuanto a España, en general, y a Castilla, en particular, unos cuantos estudiosos han afirmado en el pasado, ${ }^{23}$ y siguen repitiendo hoy en día, ${ }^{24}$ que también allí, en

18 Hay una edición crítica de la obra con traducción al español al cuidado de Arbea (2008a). También ha publicado el texto, tratando en particular en las notas de la influencia de Terencio, Gandía Esteve (1996-1967).

19 Véanse Grismer (1944, 60), Casas Homs (1953, 83-88), Stäuble (1964), Gil Fernández (1984, 98), Arbea (2008b) y Viti (2000).

20 En su comedia Cassaria (1508) siguió como modelo Mostellaria, Poenulus y Rudens de Plauto, y también Andria y Heautontimorumenos de Terencio; mientras que entre las fuentes directas de I Suppositi (1509) se pueden contar Captivi y Menaechmi del primero, y Eunucus y Heautontimorumenos del segundo; por último su Negromante (1530) se basa en Andria, Phormio y Hecyra. Véanse Grismer (1944, 66-75; en 73-75 hay un listado de comedias de autores italianos que siguieron muy de cerca a Plauto); Rubio (1991, I, lv); López - Pociña (2007, 153).

21 Su Calandra (1512) temáticamente se relaciona directamente a Testo Meneaechmi de Plauto (Grismer 1944, 71-2; Padoan 1996, 28).

22 Machiavelli tradujo Andria de Terencio (1517-1520) y compuso la comedia Clizia (1525), que deriva directamente de la la comedia Casina.

23 «De los autores profanos se leían las comedias de Terencio y algunas cosas de Ovidio. Generalmente los discípulos, cuando los maestros les daban a escoger, preferían la Aurora a Terencio, y el Tobías y los Evangelios a las Elegías del Ponto» (Olmedo 1944, 37); «Ovidio y Terencio... se leían y comentaban en todas las escuelas de Gramática, sin protesta de nadie» (ib., 163); «An important factor for the increase of intelligence concerning Terence was doubtless the fact that the plays were used as a textbook. For some time, evidently, they had been used in the grammar course at the University of Salamanca» (Webber 1956, 200-201); «In addition to classroom study of Terence, performance or at least dramatic reading of the dialogue of classical and humanistic works seems to have been a regular custom» (Gilman 1972, 312).

24 «Es en el siglo XV cuando en España se empieza a conocer a Terencio de una manera directa... En el último tercio de esta centuria, por influjos venidos de Italia, hace su aparición Terencio en la escuela... los profesores italianos, como Nicolao Antonio... y Pomponio Mantuano... trajeron auras vivificadoras de Italia» (Gil Fernández 1984, 99); «Esta actividad teatral se desarrolla sobre todo a partir de la última década del siglo XV y su 
las escuelas y las universidades, Terencio era el autor favorito para el aprendizaje del latín. ${ }^{25}$ El problema general de esta aseveración es que, con anterioridad al siglo XV, se conserva una sola alusión a la posible enseñanza del comediógrafo de Cartago en el ateneo salmantino. En los Libros de Claustros, con referencia al 15 de marzo de 1473, esto es lo que afirmó el maestro de gramática Juan Roqueno:

antes de medio día entre las 10 y las 11 horas, en presencia de Juan López notario del dicho estudio, pregunté en alta voz a todos los oyentes, que ende estaban, que serían cuatrocientos e cincuenta, si eran contentos todos que leyese el dicho libro de Tobías en lugar de Terencio, después de acabado el Salterio, que se había acabado, como digo, el jueves anterior, y todos una voce dicentes, respondieron que sí, y yo pedí testimonio de ello al dicho notario. (apud Olmedo 1944, 37)

Esta es, y sigue siendo, la única referencia a Terencio anterior al siglo XV relacionada con una universidad castellana. Lamentablemente, el hecho de que no se conserven los Libros de claustros de la Universidad de Salamanca entre los años 1481 y 1502 , no nos permite tener más informaciones acerca del asunto en cuestión.

Sobre el conocimiento de Plauto y Terencio en la España del siglo XV, aunque también en este caso se siga repitiendo que la obra de los dos cómicos era muy difundida, en realidad las noticias que se tienen no son, a nuestro jucio, muy confortantes. ${ }^{26}$ Como ha señalado Webber $(1950,1956)$ las referencias a los dos comediógrafos por parte de autores castellanos como Enrique de Villena (1384-1434), Juan de Mena (1411-1456), el Marqués de Santillana (1398-1458), el príncipe de Viana (1421-1461), Diego de Valera (1412-1488) y Fernando de Pulgar (¿1436?-¿1493?), no son concluyentes y están lejos de probar un conocimiento directo de los textos de los dos dramaturgos.

Los únicos dos escritores castellanos que parecen tener alguna familiaridad con los autores en cuestión son Alonso Fernández de Madrigal (1410-1455), el Tostado, y Alfonso de Palencia (1423-1492). Del primero, según Webber $(1956,198)$, no hay dudas de que leyó las comedias de Terencio, puesto que menciona al comediógrafo y también cita pasajes de sus comedias en diferente ocasiones, mientras que la posible influencia o presencia de Plauto en sus obras es bastante incierta $(i b ., 205)$. En cuanto a Alfonso de Palencia, casi seguramente tuvo un conocimiento bastante profundo de la obra del cartaginés. De hecho, no solo poseyó un comentario de Donato super Andriam et Eunuchum en pergamino y escrito con letra humanística italiana que adquirió en Valencia (el actual ms. 78 de la Biblioteca Universitaria de Salamanca), ${ }^{27}$ sino que también transcribió de su puño y letra en 1471 las seis comedias de Terencio (el códice se conserva hoy en día en la Biblioteca Centrale della Regione Sicilia de

punto de arranque es el estudio y consiguiente representación de las obras de Plauto y Terencio» (Alonso Asenjo 1998, 164); etc.

25 Naturalmente se han señalado solo unos críticos representativos, aun porque la mayoría de los estudiosos que tratan o han tratado de la cuestión reenvían todos, o casi todos, al estudio de Olmedo (1944) y/o de Webber (1956).

26 Además de los trabajos que se citarán a continuación en el texto y en las notas véanse, para una visión de conjunto, García-Hernández et alii (2013) y Marqués López (2015).

27 El códice en cuestión perteneció al Colegio Viejo de San Bartolomé de Salamanca y pasó luego al patrimonio bibliográfico de la Biblioteca Universitaria salmantina (Framiñán de Miguel 2002, 1188). Esta es la nota autógrafa del humanista castellano que se lee en la primera hoja de guarda: Apud Valentiam emit Alfonsus Palentinus pro pretio 19 ff. auri Aragoniae (Monfasani 1989, 232). 
Palermo con signatura MS I.C.3) ${ }^{28}$ Además a él se debe el único claro ejemplo de imitación terenciana en una obra castellana del siglo XV: se encuentra en una de sus cartas, donde presenta tres breves monólogos de, respectivamente, una mujer intoxicada, una alcahueta y una prostituta. ${ }^{29}$ Por último, aunque no nos queden pruebas directas, el historiador conoció con toda probabilidad también la obra de Plauto. ${ }^{30}$

Sin embargo, estamos convencidos de que lo que de verdad le importaba a Palencia no eran las comedias de Plauto y Terencio en sí (es decir, como textos teatrales): el suyo era, más bien, un interés lingüístico, de vocabulario. Nuestra suposición se basa en el hecho de que el CORDE registra, entre 1400 y 1501, 72 recurrencias del nombre de Terencio en obras castellanas, y de estas 65 vienen del Universal vocabulario en latín y romance del palentino, hecho que, a nuestra manera de ver, demuestra su deseo de conocer detenidamente la obra del cómico por su lenguaje. Lo mismo pasa con Plauto: de las 181 citas que recoge el CORDE, 169 vienen, como antes, del Universal vocabulario.

En cuanto al hecho de que se conserven en bibliotecas españolas tanto manuscritos como ediciones de la obra de los dos, también en este caso creemos que es necesario moverse con cautela. Si por un lado es verdad que la mayoría de los códices de Plauto y Terencia que se encuentran hoy en día en España remonta al siglo XV (Webber 1957), por otro también es verdad que antes habrá de determinar su proveniencia y cuándo, estos manuscritos, se incorporaron en los fondos de dichas instituciones. El mismo discurso vale para los impresos que se conservan actualmente en España, sobre todo si salieron de los talleres tipográficos de otros países. ${ }^{31}$

Según Webber (1957), de todos modos, la demanda de ediciones de los dos cómicos en España se suplía con la importación de ejemplares desde centros tipográficos de primer nivel, sobre todo, italianos, y aporta toda una serie de datos que parecen indicar un particular interés en el comercio de las comedias de Plauto y Terencio circunscrito, principalmente, a Valencia. ${ }^{32}$

28 Así reza el colophon autógrafo: Sex Terentii has comoedias transcripsit sibi Alfonsus Palentinus, historiographus. Finite sunt $7^{\circ}$ die Ian., anno a nat(ivitate) domini $M^{\circ}$ cccllxxi (ib.).

29 Di Camillo (2010, 129 n.). El texto puede leerse en Tate y Alemany Ferrer (1982, 52-6).

30 Mucho más escasa fue la fortuna de Plauto. Acerca de su presencia en la España tardo-medieval sabemos, gracias a las investigaciones de Sabbadini (1905-14, 137-8), que cuando Angelo Decembrio se fue a España alrededor de la mitad del siglo XV, llevó consigo un códice con todo el corpus plautino -las ocho comedias ya conocidas más las 12 de recién descubrimiento-. Además, durante su permanencia allí copió un comentario a Terencio, del que no nos quedan más informaciones.

31 Un indicio indirecto sobre las comedias de Terencio viene, tal vez, del catálogo de 1533 de los libros que se conservaban en la Biblioteca Capitular de la Catedral de Salamanca donde aparecen una Glossa de Terentio y un Terentius que, quizá, formaban parte de dichos fondos ya en 1480 (Framiñán de Miguel 2002, 1188). Los argumentos esgrimidos por la estudiosa son, en realidad, bastante débiles. Framiñán de Miguel presenta su conjetura basándose en el hecho de que la mayoría de los volúmenes que se encontraban en dicha biblioteca provenían de donaciones por parte de obispos en 1480 y 1510 , y puesto que en el inventario de esta última no se hace referencia a Terencio y a su comentario, opina que probablemente los dos textos formaban parte de la primera gran aportación, es decir, la de 1480. En total desacuerdo nos encontramos con la aseveración siguiente (2002, 1189), donde la investigadora habla de la relación de libros de la Universidad de Salamanca de 1610, y subraya la importancia del hecho de que en dicho inventario se conservaban un Pedaço de Donato sobre Terençio y cinco ejemplares de Plauto, de los cuales tres llevaban la fecha de 1494, 1511 y 1517. Primero, el documento en que se basa la estudiosa es de principios del siglo XVII y habría que ver, como ya dijimos hace poco, cuándo estas obras entraron a formar parte de la biblioteca de la universidad salmantina; segundo, los años de impresión señalados no implican en absoluto que las comedias de Plauto se encontraban allí desde aquel entonces.

32 «A book inventory (Oct. 1490) of Juan Rix, the Valencian book seller, included 30 copies of Terrencio siue Donato» y un ejemplar de Plauto; «In the book inventory (June 27, 1489) of D. Matías Mercader, an archdeacon of Valencia, appeared a copy of Donatus super Terencio con comento» y una de Plauto (Webber 1957, 34-5). 
Hay que señalar, además, las ediciones (parciales o completas) de los dos autores en cuestión que vieron la luz en España y considerar también las obras que se inspiraron claramente en ellos, así como, los comentarios y las traducciones españolas de las comedias que se llevaron a cabo.

En cuanto a Terencio, hay un raro $^{33}$ incunable que se imprimió en Barcelona, por Juan Rosembach, en $1498,{ }^{34}$ mientras que en el siglo XVI se cuentan hasta diez ediciones, ${ }^{35}$ dos de las cuales bilingües. ${ }^{36}$ Alrededor de 1530 probablemente se representó, en Valencia, la tragicomedia latina Gastrimargus de Jaime Romañá, ${ }^{37}$ que sigue como modelo a Terencio, y de 1569 es el comentario a Andria de Pedro de Figueroa (Castro de Castro 2007). Por último, no nos ha quedado ninguna traducción de sus comedias anterior al siglo XV. La primera conocida es, según Webber $(1957,32)$, la de Bernardino, racionero de Salamanca, de 1574, manuscrita. ${ }^{38}$ Sigue luego la más famosa, es decir, la de Pedro Simón Abril que se editó en 1577 en Salamanca y luego en 1583 en Alcalá (Rubiera Fernández 2009).

En lo tocante a Plauto, se han podido localizar las siguientes ediciones: Alcalá, 1517 (las primeras diez comedias); Alcalá, 1518 (las últimas diez comedias); Salamanca, 1554 (solo Aulularia); y Amberes, 1566 (todo el corpus). ${ }^{39}$ Este número limitado de ediciones con respecto a Terencio está compensado, por otro lado, por las traducciones españolas de que fue objeto Amphitruo de Plauto. La primera que se conoce es la del médico Francisco López de Villalobos, ${ }^{40}$ llevada a cabo en 1515 y que se editó en Alcalá, por Brocar, en 1517. De alrededor de 1525 es la adaptación

33 El ISTC registra solo dos ejemplares: uno en la Biblioteca Museo Víctor Balaguera i Cirera de Villanueva y Geltrú (a mitad de camino entre Barcelona y Tarragona), y otro en el Rosenbach Museum \& Library de Philadelphia.

34 Rubio cita un comentario Super Terentii comoediis editado en Tarragona, por Rosembach, en 1498: «Las ediciones españolas de Terencio forman un grupo considerable. Ya en el siglo XV aparece la primera en Barcelona en 1498: Terentius cum duobus commentis. Los dos comentarios son el de Donato y el de Johannes Calphurnius. Este incunable es extremadamente raro, como lo es igualmente otro impreso el mismo año en Tarragona (impr. Rosenbach): Super Terentii comoediis» (1991, vol. 1, lxxiv-lxxv). En realidad, creemos que se trata de una duplicación: dicha edición no es sino el incunable de las comedias del que se ha hablado hace poco, como demuestra el hecho de que la fecha de impresión del supuesto comentario y de la edición de la obra del cartaginés es la misma: 17 de marzo de 1498. Véanse Haebler (1903-17, núm. 236) y el ISTC.

35 Tanto Gil Fernández (1984, 104-105), que se basa en Palau (1948-77), como Rubio (1991, vol.1, 1xxiv-lxxv) concuerdan en el número total de ediciones que se imprimieron en el siglo XVI (es decir, diez), pero aportan fechas y lugares diferentes. Dado que esta no es, de todos modos, una información fundamental para nuestra investigación, y que de momento nos encontramos imposibilitados en dirimir la cuestión -pero sí pensamos ocuparnos del asunto en futuro-, se presentan a continuación los datos de ambos estudiosos. Los dos críticos coinciden en estos impresos: 1524 (Zaragoza), 1552 (Medina del Campo), 1577 (Salamanca, traducción de Pedro Simón de Abril), 1579 (Salamanca; dos ediciones según Gil, una según Rubio), y 1583 (Alcalá, traducción de Pedro Simón de Abril). A estas, Gil añade: una de fecha incierta al cuidado de Nebrija en Alcalá (que se reeditó luego en Zaragoza en 1524), 1549 (Lovaina), 1559 y 1565 (Valencia). Mientras que Rubio señala: 1569 (Valencia), 1577, 1585 y 1589 (Barcelona).

36 Gil Fernández $(1984,105)$ habla de once ediciones del siglo XVI, de las cuales tres bilingües, pero en el listado que presenta solo se han podido encontrar diez.

37 El texto ha sido estudiado, editado y traducido por Alonso Asenjo y Molina Sánchez (2007). Véase también el artículo de Molina Sánchez (2007).

38 El estudioso recoge la información en Zarco Cuevas (1924-29, III, 472, n. 30).

39 Toda la información viene del CCPB (Catálogo Colectivo del Patrimonio Bibliográfico Español). A estas ediciones habría que añadir, tal vez, otra más que señala Webber $(1957,35)$ : se trataría de un impreso de Salamanca de 1581 con solo el texto de Menaechmi del cual no se han podido localizar ejemplares.

40 Sobre este personaje véase Granjel (1979) y Riera Palmero y Riera Climent (2013). Acerca de su traducción pueden consultarse Baca (1969), Tremallo (1989), Ibáñez Pérez (1990), Quintero (1990), Garrido Camacho (1999), Illades (1999) y Marqués López (2001). 
de la misma comedia plautina por Fernán Pérez de Oliva. Luego se conserva una versión anónima, que combina las dos traducciones/adaptaciones precedentes, impresa en Toledo, 1554, y, por último, la reelaboración de Juan de Timoneda de 1559 (Quintero 1990).

¿Qué conclusiones se pueden sacar de los datos que se han enumerado a lo largo del presente trabajo?

En cuanto al uso de las comedias de Plauto y Terencio en la enseñanza del latín en las universidades españolas, con anterioridad a 1500, nos quedamos con una sola referencia a este último. Por sí misma podría indicar algo, pero lo que es bastante singular es que, de todos modos, no nos queden otros indicios, como comentarios, alusiones, paráfrasis, citas consistentes en obras españolas de la época, que puedan comprobar una lectura directa de la obra de los dos cómicos latinos. Con respecto a este último punto, tampoco nos queda muy claro si se conocían y con qué profundidad las obras de Plauto y Terencio en la España del siglo XV. Hay sí referencias, aunque muy genéricas, en autores castellanos de la primera mitad del siglo y, con más frecuencia, de la segunda mitad, pero el asunto no permite llegar a una conclusión definitiva. ${ }^{41}$

Si no consideramos el pasaje del Libro de claustro citado antes, las primeras noticias seguras acerca de Terencio como texto base en la enseñanza del latín, remontan al siglo XVI. En los Libros de cuenta de la Universidad de Salamanca de 1552 con referencia al bachiller Juan de Zamora, «lector de Terençio de esta Universidad», se lee que:

Avía cuarenta años que leía gramática, e así mismo hera onbre muy biejo... e que para leher y pronunçiar le faltava la dentadura, por lo qual podía haçer muy poco provecho, e así no tenía oyentes porque no le podían entender, e si algunos le iban a oír, hera más por le ir a cocar que por le ir a oír. (apud Framiñan de Miguel 2002, 1191)

De 1538 son los Estatutos de la Universidad de Salamanca cuya redacción, de todos modos, remonta por lo menos a 1529 cuando era rector del ateneo salmantino el ya citado Fernán Pérez de Oliva. En los Estatutos de 1529, el título xxvii, núms. 201225, se ocupa de reglamentar los cursos de gramática menores, medianos y mayores. En los cursos de menores, después de haber acabado con los primeros tres libros de la Gramática de Nebrija había que explicarse el cuarto y «a la tarde de primera comedia del Terencio, dos partes de versos, y despues de leydos platiquen las partes por este, preguntando a cada discipulo e provando por declinaciones, preteritos e supinos» (Tít. XXVII, núm. 207; Fuertes Herreros 1984, 168); en cuanto a los cursos medianos, está escrito que «cada un año representen dos comedias... y sean anbas de Terencio, o la una del Terencio e la otra de Plauto, esto hagan quinze dias antes de San Juan o quinze dias despues, y el que dellos no lo hiziere sea multado en seys ducados de su salario para el arca del estudio» (Tít. XXVII, núm. 217; ib.: 171). Aunque las reglamentacio-

41 Crosas López $(2010,106)$, basándose de todos modos en Webber (1950, 1956 y 1957), llega a la misma conclusión: «ni en Enrique de Villena, ni en Juan de Mena, ni en el Marqués de Santillana, en cuya biblioteca no había ningún ejemplar del cómico, ni en otros autores, como el traductor de la Genealogia deorum de Boccaccio, el príncipe de Viana, Diego de Valera y Fernando del Pulgar, las alusiones permiten detectar un conocimiento directo de Terencio... Sólo el Tostado demuestra haber leído en el original a Terencio, a quien no sólo menciona sino que cita textualmente» (106). 
nes de 1529 no fueron sino un primer esbozo de las que se iban a aprobar y publicar nueve años más tarde (Valero García 1988, 359-84), sin embargo los efectos de las mismas pueden verse ya desde 1530, año en que unos bachilleres de gramática que enseñaban en la universidad fueron multados porque no representaron «la tragedia o comedia como lo manda el Estatuto» (Framiñán de Miguel 2002, 1196). ${ }^{42}$ Y ya en la segunda mitad del siglo son abundantes las informaciones que se tienen acerca del uso de Terencio como texto-base en la enseñanza del latín, las representaciones tanto de la obra de los dos cómicos y tragedias de autores clásicos como de dramas escritos por autores de la época, que demuestran, sin lugar a duda, como ya tanto Plauto como Terencio formaban parte del patrimonio cultural español. ${ }^{43}$

En fin, en lo tocante al siglo XV, ¿las comedias de los dos dramaturgos clásicos latinos se seguían en la enseñanza del latín en Castilla? ¿El conocimiento de sus comedias era bastante extendido? Nosotros seguimos teniendo unas cuantas dudas, y hasta que investigaciones futuras no prueben lo contrario, no podremos hacer otra cosa que recomendar mayor cautela a quien se ocupe de o haga referencia a estos asuntos sin aportar información adicional alguna.

\section{Referencias bibliográficas}

Alejo Montes, F. J. (1993-94), «Los colegios de gramática en la Universidad de Salamanca en el siglo XVI», Historia de la educación XII-XIII, 309-326.

Alejo Montes, F. J. (1998), La Universidad de Salamanca bajo Felipe II: 1575-1598, Valladolid: Juan de Castilla-León, Consejería de Educación y Cultura.

Alonso Asenjo, J. (1998), «Panorámica del teatro estudiantil del Renacimiento español», en Chiabò M. y F. Doglio (coords.), Spettacoli studenteschi nell'Europa Umanistica, Roma, Torre d'Orfeo Editrice, 151-191.

Alonso Asenjo, J. y M. Molina Sánchez (eds.) (2007), Jaime Romañá / Jaume Romanyà, Tragicomedia Gastrimargus, Granada, Ediciones Universidad de Granada.

Álvarez Aranguren, L. (1990), «La reforma de los estudios de Gramática en el siglo XVI promovida por Fray Luis de León», Revista de Ciencias de las Educación 143, 231-246.

Arbea, A. (ed.) (2008a), Iohannes de Vallata, Poliodoro. Comedia humanística latina, Santiago de Chile, Ediciones Tácitas.

Arbea, A. (2008b), «Las fuentes literarias de la comedia humanística latina Bophilaria, de Egidio Gallo», Onomázein 18, 153-171.

Baca, A. R. (1969), «A Study and Comparison of the Amphitryon Theme in Francisco de Villalobos and Juan de Timoneda», Hispanofila 35, 1-17.

Bausi, F. (1991), «Note sul Prologo ai ‘Menecmi’ del Poliziano», Interpres XI, 357-64.

Bertini, F. (1997), Plauto e dintorni, Bari, Laterza.

Billanovich, G. (1978), «L'insegnamento della grammatica e della retorica nelle università italiane tra il Petrarca e il Guarino», en Ijsewijn J.-Jacques Paquet J. (eds.), The Universities in the Late Middle Ages, Leuven, Leuven University Press, 365-380.

42 Además del artículo ya citado de Framiñán de Miguel (2002), tratan de los Estudios de Gramática de la Universidad de Salamanca durante el siglo XVI, Álvarez Aranguren (1990) y Alejo Montes (1993-94; 1998).

43 Para el conocimiento de las obras de Plauto y Terencio y su influencia en obras españolas del siglo XVI, véanse, entre otros, Gil Fernández (1984), Alonso Asenjo (1998), Picón García (2006), Pascual Barea (2013) y Molina Sánchez (2015). 
Bombieri, G. (1985), «Osservazioni sul Prologo ai Menecmi di Angelo Poliziano», en Cardini R. -E. Garin-L. Cesarini Martinelli-G. Pascucci (eds.), Tradizione classica e letteratura umanistica. Per Alessandro Perosa, Roma, Bulzoni, vol. II, 489-506.

Bucchioni, U. (1911), Terenzio nel Rinascimento, Rocca San Casciano, Licinio Cappelli.

Casas Homs, J. M. (ed.) (1953), Johannes de Vallata, Poliodorus, comedia humanística desconocida, Madrid, CSIC.

Castro de Castro, J. D. (2007), «El comentario a la Andria (1569) de Pedro de Figueroa: sus fuentes», Myrtia: Revista de filología clásica 22, 181-205.

$C C P B=$ Catálogo Colectivo del Patrimonio Bibliográfico Español, en línea, <http://www. mcu.es/bibliotecas/MC/CCPB/index.html> [16/02/2017].

Chevalier, J.-F. (2013), «Neo-Latin Theatre in Italy», en Bloemendal J.-H. B. Norland (eds.), Neo-Latin Drama and Theatre in Early Modern Europe, Leiden-Boston, Brill, 25-102.

Conte, G. B. (1984), Letteratura latina. Manuale storico dalle origini alla fine dell'impero romano, Firenze, Le Monnier.

CORDE $=$ Corpus diacrónico del español. Real Academia Española, en línea, $<\mathrm{http}: / / \mathrm{www}$. rae.es> [16/02/2017].

Cortesi, M. (1980), «Libri e vicende di Vittorino da Feltre», Italia Medievale e Umanistica XXIII, 77-114.

Crosas López, F. (2010), De enanos y gigantes. Tradición clásica en la cultura medieval hispánica, Universidad Carlos III de Madrid, en línea, $<$ https://e-archivo.uc3m.es/handle/10016/8346>.

DBI = Dizionario biografico degli italiani, Roma, Istituto della Enciclopedia Italiana, 1962-, en línea, <http://www.treccani.it/Portale/ricerche/searchBiografie.html> [17/02/2017].

Del Lungo, I. (1876), «Di altre recitazioni di commedie latine in Firenze nel sec. Xv», Archivio Storico Italiano 23, 170-175.

Di Camillo, O. (2010), «When and Where was the First Act of La Celestina Composed? A Reconsideration», en Paolini D. (coord.), «De ninguna cosa es alegre posesión sin compañia». Estudios celestinescos y medievales en honor del profesor Joseph Thomas Snow, New York, Hispanic Seminary of Medieval Studies, vol. 1, 91-157.

Doglio, F. (1971), «Il teatro in latino nel Cinquecento», en Il teatro classico italiano nel '500, Roma, 164-196.

Doglio, F. (1982), «La commedia umanistica fra le università e le corti italiane del Quattrocento», en Teatro in Europa. Storia e documenti, Milano, Garzanti, vol. 1, 405-456.

Framiñán de Miguel, M. J. (2002), «Actividad dramática en el Estudio salmantino del Renacimiento: Plauto y Terencio», en Humanismo y Pervivencia del Mundo Clásico III: Homenaje al Profesor Antonio Fontán, Alcañiz-Cádiz, Instituto de Estudios Humanísticos, Ediciones del Laberinto, vol. 3, 1187-1200.

Fuertes Herreros, J. L. (ed.) (1984), Estatutos de la Universidad de Salamanca, 1529. Mandato de Pérez de Oliva, Rector, Salamanca, Universidad de Salamanca.

Gandía Esteve, J. (ed. y trad.) (1996-97), «Comedia Poliscena». Lemir. Revista Española de Literatura Medieval y del Renacimiento 1, en línea, <http://parnaseo.uv.es/Lemir/Revista.html> [17/02/2017].

García-Hernández, B.-R. López Gregoris-C. González-Vázquez (2013), «La recepción de Plauto y Terencio en la literatura española», en Douglas Olson, S. (ed.), Ancient Comedy and Reception. Essays in Honor of Jeffrey Henderson, Berlin / New York, De Gruyter, 606-653. 
Garin, E. (1958), Il pensiero pedagogico dello Umanesimo, Firenze, Coedizioni Giuntine Sansoni.

Garrido Camacho, P. (1999), El tema del reconocimiento en el teatro español del siglo xvi. La teoría de la anagnórisis, Madrid, Editorial Támesis.

Giannetto, N. (1981), Vittorino da Feltre e la sua scuola: umanesimo, pedagogia e arti, Firenze, Olschki.

Gil Fernández, L. (1984), «Terencio en España: del Medievo a la Ilustración», en Estudios de humanismo y tradición clásica, Madrid, Editorial de la Universidad Complutense, 95-125.

Gilman, S. (1972), The Spain of Fernando de Rojas: The Intellectual and Social Landscape of «La Celestina», Princeton, Princeton University Press.

González-Haba, M. (ed.) (1992), Plauto, Comedias, Madrid, Gredos.

Granjel, L. S. (1979), Vida y obra de López de Villalobos, Salamanca, Universidad de Salamanca.

Grismer, R. L. (1944), The Influence of Plautus in Spain before Lope de Vega, New York, Hispanic Institute.

Haebler, K. (1903-17), Bibliografía Ibérica del siglo XV, La Haya, Leipzig, Martinus Nijhoff, Karl W. Hiersemann, 2 vóls.

Pérez Ibáñez, M. J. (1990), «La traducción de Anfitrión del doctor López de Villalobos», Minerva 4, 255-276.

Illades Aguiar, G. (1999), La Celestina en el taller salmantino, México, Universidad Nacional Autónoma de México.

ISTC = Incunabula Short Title Catalogue, The British Library, en línea, <http://www.bl.uk/ catalogues/istc/> [17/02/2017].

Lattanzi Roselli, R. (ed.) (1973), Angelo Poliziano, La commedia antica e l'Andria di Terenzio, Firenze, Sansoni.

López, A.-A. Pociña (2007), Comedia romana, Madrid, Akal.

Marqués López, E. (2001), «La presencia de Plauto en España. Primeras traducciones del siglo XVI», en Strosetzki, C. (ed.), Actas del V Congreso de la Asociación Internacional Siglo de Oro (AISO), Frankfurt am Main / Madrid, Vervuert / Iberoamericana, 841-851.

Marqués López, E. (2015), Recepción e influencia del teatro de Plauto en la literatura española, tesis doctoral, Universidad de La Rioja, Servicio de Publicaciones, 2015 [según Dialnet.com la tesis fue defendida en el año 2003], en línea, $<$ https://dialnet.unirioja.es/ servlet/tesis?codigo $=97>[17 / 02 / 2017]$.

Martelli, M. (1993), «Il prologo di Poliziano ai 'Menaechmi' di Plauto», en Gavazzeni F.-G. Gorni (eds.), Le tradizioni del testo. Studi di letteratura italiana offerri a Domenico de Robertis, Milano-Napoli, Ricciardi, 69-83.

Mercer, R. G. G. (1979), The Teaching of Gasparino Barzizza. With special reference to his place in Paduan Humanism, London, Duckworth.

Molina Sánchez, M. (2007), «Plauto y Terencio en el Renacimiento español: la Tragicomedia Gastrimargus de Jaime Romañá», Florentia iliberritana: Revista de estudios de antigüedad clásica 18, 311-331.

Molina Sánchez, M. (2015), «El teatro humanístico español: claves para su estudio», en Macías Villalobos, C.-J. Mª Maestre Maestre-J. F. Martos Montiel (eds.), Europa Renascens. La cultura clásica en Andalucía y su proyección europea, Zaragoza, 2015, 853882.

Monfasani, J. (1989), «Bernardo Giustiniani and Alfonso de Palencia: Their Hands and Some New Humanist Texts and Translations», Scriptorium 43.2, 223-238.

Olmedo, F. G. (1944), Nebrija en Salamanca (1475-1513), Madrid, Editora Nacional. 
Orlando, V. (1940), «Le edizioni rinascimentali dei volgarizzamenti di Plauto e Terenzio», Aevum XVI, 573-581.

Pacetto, G. (1919), La fortuna di Terenzio nel Medioevo e nel Rinascimento, Catania, Tipografia Viaggio-Campo.

Padoan, G. (1982), La commedia rinascimentale veneta (1433-1565), Vicenza, Neri Pozza.

Padoan, G. (1996), L'avventura della commedia rinascimentale, Padova, Piccinin.

Palau y Dulcet, A. (1948-77), Manual del librero hispanoamericano, $2^{\mathrm{a}}$ ed., corr. y aum., Barcelona, Librería Palau; Oxford, The Dolphin Books Co.

Pandolfi, V.-E. Artese (1965), Teatro goliardico dell'Umanesimo, Milano, Lerici.

Paolini, D. (2011), «Sobre un tópico equivocado (las representaciones de las comedias de Plauto y Terencio en España a finales del siglo XV) y Celestina», Celestinesca 35, 67-84.

Paolini, D. (2012), «La comedia humanística, La Celestina y España», en Botta, P. (coord.), Rumbos del hispanismo en el umbral del Cincuentenario de la AIH, Roma, Bagatto Libri, vol. 2 (Medieval), 281-287.

Pascual Barea, J. (2013), «Neo-Latin Drama in Spain, Portugal and Latin America», en J. Bloemendal-H. B. Norland (eds.), Neo-Latin Drama and Theatre in Early Modern Europe, Leiden-Boston, 545-632.

Perosa, A. (1965), Teatro umanistico, Milano, Nuova Accademia.

Picón García, V. (2006), «El teatro neo-latino humanístico y escolar en España en el siglo XVI», en Tavares de Pinho, S. (coord.), Teatro Neolatino em Portugal no Contexto da Europa: 450 Anos de Diogo de Teive, Coimbra, 39-95.

Pintor, F. (1906), Le prime recitazioni di commedie latine in Firenze nel sec. XV, Perugia, Miscellanea nuziale Ferrari-Toniolo.

Pittaluga, S. (2001), La scena interdetta. Teatro e letteratura fra Medioevo e Umanesimo, Napoli, Liguori.

Prete, S. (1990), «Gli studi sulle commedie di Terenzio nel Rinascimento», en Capitoli su Terenzio, Sassoferrato, Istituto Internazionale di Studi Piceni, 13-33.

Questa, C. (1968), Per la storia del testo di Plauto nell'Umanesimo Roma, Edizioni dell'Ateneo.

Quintero, M. C. (1990), «The Interaction of Text and Culture in Spanish Renaissance 'Translations' of Plautus' Amphytruo», Bulletin of Hispanic Studies LXVII, 235-252.

Riera Palmero, J.-C. Riera Climent (2013), «Francisco López de Villalobos (1474-1549), un médico y poeta judeoconverso en el Renacimiento castellano», Llull: Revista de la Sociedad Española de Historia de las Ciencias y de las Técnicas 36.78, 359-386.

Ronconi, A. (1970), «Sulla fortuna di Plauto e Terenzio nel mondo romano», Maia 22, 19-37 [reimpreso con el título de «La critica plautina e terenziana nel mondo romano», en su Interpretazioni letterarie nei classici, Firenze, Le Monnier, 1972, 142-168].

Rossi, V. (1992), Il Quattrocento, Padua, Piccin Nuova Libraria; Milán, F. Vallardi.

Rubiera Fernández, J. (2009), Para entender el cómico artificio. Terencio, Donato-Evancio y la traducción de Pedro Simón Abril (1577), Vigo, Academia del Hispanismo.

Rubio, L. (ed. y trad.) (1991), Terencio, Comedias, Madrid, CSIC, 3 vóls.

Ruggio, Luca (2011), Repertorio bibliografico del teatro umanistico, Firenze, SISMEL-Edizioni del Galluzzo.

Sabbadini, R. (1897), «Biografi e commentatori di Terenzio», Studi italiani di filologia classica $\mathrm{V}, 289-327$.

Sabbadini, R. (1905-14), Le scoperte dei codici latini e greci nei secoli XIV e XV, Firenze, Sansoni.

Stäuble, A. (1968), La commedia umanistica del Quattrocento, Firenze, Istituto Nazionale di Studi sul Rinascimento. 
Stäuble, A. (1972), «Risonanze europee della commedia umanistica del Quattrocento», en Verbeke, Mag. G.-J. Ijsewijn (eds.), The Late Middle Ages and the Dawn of Humanism Outside Italy, Leuven, The Hague, University Press, Martinus Nijhoff, 182-194.

Stäuble, A. (1976), «La commedia umanistica: bilancio e prospettive», Maia 28, 255-265.

Stäuble, A. (1986), «Umanistica, commedia», en Branca, V. (coord.), Dizionario critico della letteratura italiana, Torino, UTET, vol. IV, 344-349.

Tate, R. B.-R. Alemany Ferrer (eds.) (1982), Alfonso de Palencia, Epístolas Latinas, Bellaterra, Universidad Autónoma de Barcelona.

Tremallo, B. S. (1989), «El Anfitrión de Francisco Lopez Villalobos», Anuario de Letras 27, 313-328.

Valero García, P. (1988), La Universidad de Salamanca en la época de Carlos V, Salamanca, Universidad de Salamanca.

Ventrone, P. (1992), «Riflessioni teoriche sul teatro nella Firenze dei primi Medici», Interpres XII, 150-196.

Ventrone, P. (1993), Gli araldi della commedia. Teatro a Firenze nel Rinascimento, Pisa, Pacini Editore.

Villa, C. (1984), La 'lectura Terentii’. Da Ildemaro a Francesco Petrarca, vol. I, Padova, Antenore.

Villoresi, M. (1994), Da Guarino a Boiardo. La cultura teatrale a Ferrara nel Quattrocento, Roma, Bulzoni.

Viti, P. (1999), Immagini e immaginazioni della realtà. Ricerche sulla commedia umanistica, Firenze, Le lettere.

Viti, P. (2000), «Struttura e fonti della Philogenia di Ugolino Pisani», en Andrioli, P.-G. A. Camerino-G. Rizzo-P. Viti (coords.), Teatro, scena, rappresentazione, Galatina, Congedo, 57-65.

Zarco Cuevas, J. (1924-29), «Catálogo de los libros de su Magestad que se hallaron en poder de Serojas a... de Março, 1574», en Catálogo de los manuscritos castellanos de la Real Biblioteca de El Escorial, Madrid.

Webber, E. J. (1950), «Plautine and Terentian Cantares in Fourteenth-Century Spain», Hispanic Review 18.2, 93-107.

Webber, E. J. (1956), «The Literary Reputation of Terence and Plautus in Medieval and Pre-Renaissance Spain», Hispanic Review 24.3, 191-206.

Webber, E. J. (1957), «Manuscripts and Early Printed Editions of Terence and Plautus in Spain», Romance Philology 11.1, 29-39. 